\title{
Sexismo na escola: Presente! ${ }^{*}$
}

\author{
Sexism in school
}

\author{
Joana do Prado Puglia,' Edna Linhares Garcia' \\ 'Universidade de Santa Cruz do Sul (Unisc), Santa Cruz do Sul, RS, Brasil.
}

Recebido em: 20/08/2016 / Aceito em: 22/08/2016 / Publicado em: 30/09/2016

joanapuglia@yahoo.com.br

\section{RESUMO}

Objetivo: este estudo é resultado da análise da produção de sentido de discursos de profissionais da educação produzidos em grupos de discussão, organizados com objetivo de investigação dos efeitos da heteronormatividade dentro da escola. Método: estudo qualitativo onde foram ouvidas 58 mulheres e 10 homens, profissionais de educação em escolas estaduais. Resultados: os níveis de rejeição às homossexualidades, lesbianidades e transexualidades, ainda que disfarçados por um discurso politicamente correto, revelaram o entrecruzamento de crenças solidamente fundamentadas no sexismo e no desconhecimento a respeito da sexualidade humana e suas possibilidades. Considerações finais: percebe-se que este desconhecimento mantém preconceitos e tabus que podem estar tornando profissionais da educação guardiãs/ões da norma heterossexista, o que gera sofrimento dentro da escola. Estes resultados apontam para a necessidade de criação de políticas públicas voltadas não somente para facilitar a capacitação destas/es profissionais nos campos de estudos da sexualidade humana, mas, sobretudo para viabilizar a interdisciplinaridade dentro das escolas.

Palavras-chave: Heterossexismo; Sexismo; Profissionais da educação; Escola.

\section{ABSTRACT}

Objective: this study is the result of analysis of production towards education professionals speeches produced in discussion groups, organized with the objective of investigating the effects of heteronormativity within the school. Method: qualitative study which were heard 58 women and 10 men professional education in state schools. Results: rejection levels to homose- xualities, lesbianidades and transexualidades, although disguised by a politically correct discourse, revealed the belief crisscross solidly based on sexism and ignorance about human sexuality and its possibilities. Closing remarks: it is noticed that this ignorance keeps prejudices and taboos that may be making professional guardians of education of heterosexist norm, which generates intense suffering in school. These results point to the need to create public policies not only to facilitate the training of theses professionals in the fields of study of human sexuality, but above all to enable interdisciplinarity within schools.

Keywords: Heterosexism; Sexism; Education Professionals; School.

\section{INTRODUÇÃO}

Este estudo em escolas públicas de ensino médio teve como objetivo a escuta de profissionais da educação para fins de obtenção de dados para a pesquisa que investiga os efeitos da heteronormatividade, dentro da escola. A queixa recorrente, desde os primeiros contatos com gestoras e gestores, sempre foi de maus tratos entre alunos e alunas e perseguições, brincadeiras que perturbavam as aulas, o bullying. Neste caso, de natureza lesbo-bi-trans-homofobia. Duas escolas referiram a existência de aluno e aluna transexuais, o que parecia causar bastante incômodo para professores e professoras, principalmente nas situações de uso de banheiro e uso de nome de registro na lista de chamada. Desta forma, este pareceu mesmo ser um momento bem interessante para se realizar este estudo, quando se poderia levantar discussão de temas tão relevantes, como sexualidade, homossexualidades, heteronormatividade, heterossexismo, lesbo-trans-homofobia, violências e preconceito. 
As relações de poder dentro da escola parecem estar muito bem estabelecidas nas figuras da direção, profissionais de educação e estudantes; estes em última escala hierárquica. Porém, por trás deste aparente esquema pressuposto, paira toda uma estratégia de sobrevivência, tecida em engendramentos nada simplificados, regida por regras também nada explícitas: o dispositivo da sexualidade.

Discutir os efeitos deste dispositivo, a sexualidade, atravessado ainda pelas questões de gênero e diversidade sexual, fundamentada pela lógica de Michel Foucault, Judith Butler, Guacira Louro, Simone Beauvoir, entre muitas outras teóricas, permitirá entender o fenômeno que ora se revela neste estudo, na análise da produção de sentido dos discursos de profissionais da educação.

\section{Sexualidade, gênero e diversidade sexual}

A sexualidade, essa presença insidiosa, insistente, incontrolável, é percebida como um dispositivo de poder. Este dispositivo surge quando o sexo se tornou um foco privilegiado para o controle disciplinar do corpo e para a regulação dos fenômenos da população. Com o dispositivo da sexualidade, os mecanismos do poder se dirigem ao corpo, à vida, ao que faz proliferar, ao que reforça a espécie, vigor, capacidade de dominar, ou sua aptidão para ser utilizada. ${ }^{1}$ Saúde, progenitura, raça, futuro da espécie, vitalidade do corpo social, quando o poder fala da sexualidade e para a sexualidade.

Nas sociedades cristãs, o sexo tornou-se algo que era preciso examinar, vigiar, confessar e transformar em discurso. Podia-se falar de sexualidade, porém, somente para proibi-la. O esclarecimento e a iluminação da sexualidade se deu nos discursos e na realidade das instituições e das práticas. ${ }^{1}$ Proibições faziam parte de uma economia mais complexa. Vivemos em uma sociedade que produz discursos e que logo os transforma em discursos verdadeiros e resulta na formação de poderes específicos. Assim, estas verdades produzidas em relação à sexualidade tornaram-se um problema no Ocidente, resultando na repressão sexual. Talvez esta multiplicidade de vozes se elevando, na destituição dos poderes sagrados, até então, não questionáveis, provoquem esta estranheza que se ouve agora com frequência, na crítica aos neologismos, nas tentativas de apropriação dos fenômenos e reapropriação de identidades outrora confiscadas pelo saber médico.

Porém, sexualidade ainda é, nos dias de hoje, conceito em construção. Sexualidade é o nome que se pode dar a um dispositivo histórico e não a uma realidade subterrânea que se apreende com dificuldade, mas à grande rede da superfície em que a estimulação dos corpos, a intensificação dos prazeres, a incitação ao discurso, a formação dos conhecimentos, o reforço dos controles e das resistências, encadeiram-se uns aos outros, segundo algumas grandes estratégias de saber e de poder ${ }^{1}$.

A sexualidade é ainda um construto complexo que relaciona fatores biológicos, psicológicos, socioeconômicos, culturais, entre outros, difundida e aprendida por meio da inserção na cultura, que orienta o imaginário e comportamentos. ${ }^{2} \mathrm{E}$ a sexualidade está na escola porque faz parte dos sujeitos, independentemente se haja aula de educação sexual, se haja discursos ou intenção manifesta de se falar em sexualidade. ${ }^{3}$ Ela está lá porque não pode ser ligada ou desligada.

Pensar sexualidade, costuma remeter à limitação das possibilidades dos sujeitos, em uma lógica binária, de homem ou mulher, aprisionando-os num campo de atuação performático. ${ }^{4} \mathrm{Na}$ teoria desta autora, fica afastada a possibilidade de que sexo, gênero e sexualidade existam numa relação necessariamente mútua. De forma que se alguém é biologicamente fêmea, isto não implica que exiba características convencionalmente reconhecidas como femininas e tenha desejos por homens. A autora ainda apresenta o conceito de performance de gênero, que refere-se às práticas regulatórias na manutenção da ordem compulsória ditada pela heteronormatividade, na repetição de comportamentos, falas, modos, gestos, culturalmente instituídos, reforçando a construção de corpos masculinos e femininos em atos intencionais, gestos performativos. Não esquecendo que gênero são os significados culturais assumidos pelos corpos e, sendo assim, não se pode dizer que ele decorra do sexo desta ou daquela maneira, como se tenta impor socialmente, quando se diz que isto ou aquilo é modo de menina ou de menino. ${ }^{5}$ Pensando-se então em corpo sexuado e gênero culturalmente construído, a autora nos apresenta uma descontinuidade desta lógica associativa dos únicos dois gêneros, colados ao sexo, para fazer pensar na possibilidade de uma multiplicidade de gêneros. Desta forma, o gênero é uma identidade mantida pela reiteração e repetição destas normas que se cristalizam, como se fosse uma verdade carnal, incontestável.

Heteronormatividade é a produção e a reiteração compulsória da norma heterossexual, que só possível pelo alinhamento entre sexo, gênero e sexualidade, quando se supõe que todas as pessoas sejam, ou devam ser, heterossexuais, discriminando, privando e punindo quem ouse escapar à regra imposta. ${ }^{6}$ É a capacidade da heterossexualidade se apresentar como a lei que regula e determina a impossibilidade de vida fora das suas normas. Uma regulação que dá inteligibilidade cultural de modelo hegemônico de gênero, naturaliza corpos, gêneros, dando coerência e sentido somente se houver um sexo estável expresso mediante o gênero estável, masculino expressando homem e feminino expressando mulher. ${ }^{7}$

Vigora então a ideologia e sistema heterossexista, frente ao binômio heterossexualidade/homossexualidade, como critério distintivo para o reconhecimento da dignidade dos sujeitos e distribuição dos benefícios sociais, políticos e econômicos, uma vez que o pertencimento a grupos inferiorizados implica a restrição, quando não a supressão completa e arbitrária de direitos e de oportunidades, por razões jurídico-formais, pelo simples exercício da força física bruta ou em virtude dos efeitos simbólicos das representações sociais. ${ }^{8}$

O termo heterossexismo seria então o mais adequado para designar a discriminação contra homossexuais e por todos aqueles que desafiam a heterossexualidade como parâmetro de normalidade, ligada às raízes culturais, sociais e políticas. ${ }^{8}$ Enquanto a palavra homofobia estaria mais diretamente relacionada à dinâmica subjetiva desencadeadora do desprezo às pessoas homossexuais, como os medos e ódios. O autor ainda aponta para 
a proliferação de outros termos, objetivando designar formas correlatas e específicas de discriminação, tais como transfobia, relacionada a travestis e transexuais, a lesbofobia ligada a lésbicas e bissexualfobia voltada contra bissexuais. Desta forma, optou-se em adotar neste estudo o termo lesbo-bi-trans-homofobia, a fim de dar maior visibilidade a estas expressões do mesmo fenômeno, negando-se a invisibilizá-los.

Neste estudo objetivou-se, ouvindo profissionais da educação, descobrir quais os efeitos da heteronormatividade dentro da escola, circulando nos discursos, nos saberes, nas relações, no cotidiano de professoras e professores, alunas e alunos.

\section{MÉTODO}

O método escolhido para coleta de dados para este trabalho foi, incialmente, o de formação de grupos focais, mas, devido ao número de participantes, converteu-se em grupos de discussão. Grupos de discussão diferenciam-se dos grupos focais por expressarem opiniões que são resultados da interação do grupo e não individuais. Além disso, o grupo focal tem a característica de ser composto por pequeno número de pessoas, já que o aprofundamento da opinião individual é interessante, enquanto o grupo de discussão pode envolver grande número de participantes. ${ }^{9}$

Para o estudo dos resultados, procedeu-se à análise da produção de sentido, a partir dos discursos obtidos. Os sujeitos e sujeitas de pesquisa foram profissionais da educação de escolas de ensino médio. Todos e todas assinaram termos de consentimentos livre e esclarecido. Apenas dois, dos quatro grupos planejados, aconteceram porque as escolas E1 e E3 não desejaram formar grupos para discussão do tema. A estratégia do grupo consistiu na exibição do filme curta metragem, intitulado "Não quero voltar sozinho" como disparador das discussões. Filme que conta a história de Leonardo, um adolescente deficiente visual, que vive uma intensa mudança em sua vida com a chegada de um novo colega, Gabriel, em sua escola. A trama envolve os ciúmes da colega e melhor amiga, Giovana e a inocente descoberta do amor entre os dois rapazes. ${ }^{10}$

É nas práticas discursivas que se torna possível acessar a produção de sentido estabelecida na escala das relações interpessoais ${ }^{11}$. Entretanto, será necessário familiarizar-se com a diversidade própria ao imaginário social e sobre os objetos que são foco dos processos de significação. Práticas discursivas correspondem aos momentos ativos do uso da linguagem, onde convivem, tanto a ordem como a diversidade, envolvendo a linguagem em ação, as maneiras a partir das quais as pessoas produzem sentidos e se posicionam em relações sociais cotidianas. ${ }^{12}$

O sentido é uma construção social, um empreendimento coletivo e interativo, através do qual as pessoas, na dinâmica das relações sociais histórica e culturalmente localizadas, constroem os termos a partir dos quais compreendem e lidam com as situações e fenômenos a sua volta. ${ }^{12}$

Profissionais da educação pertenciam às áreas da matemática, da linguagem, das ciências da natureza e das ciências humanas, além de orientadoras educacionais, supervisoras de ensino, psicopedagogas, diretoras e diretores. Embora os grupos tenham se realizados em escolas localizadas em zona urbana e rural, foi interessante notar que muitos profissionais da educação desempenham suas atividades, em turnos diferentes, nestes dois ambientes e que residem na zona urbana. Os discursos foram gravados, conforme constava no termo de consentimento livre e esclarecido e depois transcrito para que pudesse ser feita a análise da produção de sentido. Quanto ao perfil da/os participantes, havia 32 mulheres (M) e 7 homens $(H)$ presentes no grupo da escola E2, enquanto que no grupo da escola E4, participaram 26 mulheres e 3 homens. Somando-se então, 58 mulheres e 10 homens, conforme o quadro demonstrativo do/as sujeito/as desta pesquisa (Quadro 1).

Após a realização dos grupos de discussão ocorreram as transcrições das gravações em áudio dos discursos para que pudesse ser feita a análise destas falas e a produção dos sentidos. Mapas foram construídos até se conseguir entender como se articulam estas ideias a partir do que foi dito. O estudo obteve parecer consubstanciado favorável pelo Comitê de Ética da Universidade de Santa Cruz do Sul sob o número 22102313.1.0000.5343.

\section{RESULTADOS}

As categorias emergem dos sentidos produzidos e materializados, neste caso, nas palavras, nos silêncios, nas metáforas, nos lapsos. A palavra carrega sentido e, quando este sentido remete a relações assimétricas de dominação e poder entre os gêneros, serão classificadas como sexistas. Entre as falas consideradas carregadas de ideologia sexista, podemos ainda detectar outros efeitos secundários, que passam a ser sub-categorizados como da responsabilização e da culpa, quando o discurso fala da auto-percepção do/a sujeito/a como responsável pelo evento ou culpada pelas consequências deste. A seguir, a análise parcial de alguns destes discursos.

\section{Aceitar ou não aceitar}

No discurso de duas professoras, os relatos de casos; no primeiro, de sua própria família, onde duas mulheres vivem uma relação homoafetiva na espera da aceitação do pai. O silêncio deste é a resposta. Fica implícito o poder deste pai na necessidade da aprovação para que se deem as mãos diante da família e, desta forma, simbolicamente, se legitimar a relação que já é

Quadro 1 - Demonstrativo do/as sujeito/as desta pesquisa.

\begin{tabular}{lcccc}
\hline Escolas & Mulheres & Homens & Total & Meio \\
\hline E2 & 32 & 07 & 39 & Urbano / centro \\
E4 & 26 & 03 & 29 & Rural / dif. Aces. \\
Total & 58 & 10 & 68 & \\
\hline
\end{tabular}


conhecida de todos. Mas, que ele mantém na invisibilidade e, principalmente, silenciada.

$M^{*}$ - Elas, elas moram juntas, na mesma casa, os filhos da mulher aceitam, só que elas evitam quando estão assim no grupo familiar de ficar ah... Se agarrando, se beijando, mas toda a famí lia... Aceita, ou não sei se é bem aceitar... Principalmente o pai dela, assim... Ele procura não.. Não questionar. E... eee um dia ela colocou prá minha mãe... Essa minha prima, que elaaa... Ela queria que o pai aceitasse assim, ãaah... Na boa, de aceitar que elas andassem de mão... Né... Que elas fossem assim andar como um casal, né. Mas ele... Ele não diz que ele é contra, mas ele também não dá abertura prá que elas... Se manifestem assim né... Então elas aparentemente assim são duas mulheres que moram junto, mas, não... Na família...

Ainda quando a professora fala na aceitação, diz que toda a família aceita a relação das duas mulheres. Depois vacila, pensa e declara desconfiar desta aceitacão. Naquele momento, quando faz a narrativa, parece perceber que a situação vivida pela prima e sua companheira não seja de aceitação pela família. Buscando o verbete aceitar no dicionário formal encontramos as seguintes definições: 1.Consentir em receber (coisa oferecida ou dada); 2 . Concordar com; 3. Ter como bom ou certo; 4. Assentir em algo. ${ }^{13}$

Não se pode saber se realmente esta família aceita a relação homoafetiva, pois ela está invisibilizada, disfarçada como amizade de duas mulheres. Mais aproximada ao conceito de aceitação está a posição delas em relação à família, pois que as duas mulheres sim concordaram com as regras do pai, consentem com a imposição dele, receberam o que Ihes foi oferecido, apesar de não parecer que tenha sido de bom grado, já que ainda tentam obter a permissão deste pai para poderem assumir a relação. Então, pode-se dizer que sejam elas quem aceitam ao pai lesbofóbico, e não o pai à filha lésbica.

O poder é também uma condição do sujeito, sem a qual ele não poderia existir como um agente. Este sujeito, mesmo imerso nas estruturas de poder, é um agente $^{14}$. O sujeito necessita do poder para ser um sujeito e sem o poder não haveria possibilidade nem para o status de sujeito e nem para agência de poder. O sujeito emerge como o efeito de um poder prévio que ele também excede, mas o poder também age sobre o um sujeito que parece anteceder, mas não o faz. Nessa relação ambivalente do sujeito com o poder, ele depende do poder para sua existência, mas também exerce poder sob formas subversivas inesperadas. Assim, podemos pensar esta relação pai e filha, de assujeitamento, a assimetria e subordinação, denunciada na própria palavra aceitar, em que já fica implícita uma superioridade, uma hierarquia do grupo familiar predominantemente heterossexual, sendo condescendente em receber entre eles e elas aquelas duas pessoas que ousam romper com a norma instituída, mas não sem restringir-lhes os direitos. Tão claro este fenômeno, que a professora, prima da vítima da discriminação familiar, gagueja, vacila em pronunciar a palavra aceitar, percebendo ao falar, os processos atravessados naquele discurso.

\section{O discurso sexista}

O sexismo compreende avaliações negativas e atos discriminatórios dirigidos às mulheres em função de sua condição de gênero ${ }^{15}$ e pode manifestar-se sob a forma institucional ou interpessoal, sendo que contextos institucionais sexistas favoreçam comportamentos e relações interpessoais sexistas. ${ }^{16}$

O segundo relato de professora apresenta uma fala sobre uma situação vivida por um aluno e, na sequência, suas colegas partem logo para a crítica sobre a mãe desta criança. Um professor também expressa sua opinião sobre a mãe, ao compará-la com uma chocadeira. Em seguida, outra colega coroa a discussão, deixando no ar o comentário que insinua que dar-se ao direito de vivenciar sua sexualidade, seus desejos e afetos seja um comportamento esperado somente de um homem.

M- A profe falou ali a questão antes de ser. pai ser de outra geração, mas eu tenho um aluno que a mãe sofreu muito com o pai dele, diversas situações. E agora ela está com uma companheira. E ele não aceita. Ele deve tá com uns quinze anos. E ele não aceita de jeito nenhum, ele já saiu de casa prá morar com outros parentes prá não tá... E ele quer por que quer, do jeito dele, forçar a mãe a largar a companheira e voltar, deixar... Ele volta prá casa se ela abandonar essa situação. E aí a gente tenta conversar na aula, a gente tenta fazer este papel de... Não, para aí, vamos rever... M- A cabeça da mãe!

M- Por quê?

M- Da mãe! Mas pensa um pouco! Primeiro... A minha concepcão assim: Depois que eu sou mãe, primeiro eu tenho que olhar pelos meus filhos. Se a minha relação não é boa com os meus filhos... Com quem vai ser? Então eu vou jogar meu filho... H- Mas existe um conceito de mãe chocadeira nessa vida. Choca e... Dá o que dá

M- É primeiro o filho, depois...

M- Se fosse homem... Claro!

M- (...) Ninguém é obrigada a ficar junto, mas assim, ó: Ah, eu tenho um, sei lá, no caso do meu pai, eu tenho um irmão lá que minha mãe nunca imaginou... Então a criança fica assim muito dividida, muito... Muito perdida. Eu acho que é nesse sentido... Eu pensaria assim, é nesse sentido. Pensar mais no filho e não se desesperar em cuidar do lado afetivo dela.

Interessante notar que em nenhum momento surge questionamento em relação ao sofrimento vivido pela mãe mencionado no início do relato, ou sobre o abandono do filho, por parte do pai. Apenas a mãe é responsabilizada, como se fosse dever somente dela os cuidados e criação do filho. Inclusive, o professor chega a mencionar o conceito de mãe chocadeira, comparando-a a uma máquina de chocar ovos.

O efeito metafórico e o deslize, ambos da ordem do simbólico, e o lugar de interpretação, da ideologia, da historicidade, são próprios da relação do discurso e da língua, uma vez que estes efeitos metafóricos e deslizes nas interpretações que apontam para a duplicidade do discurso que a psicanálise revela o inconsciente e, na 
análise do discurso envolve a ideologia. Sendo assim, é nos deslizes dos sentidos que o efeito metafórico está na base de constituição dos sentidos dos sujeitos. ${ }^{17} \mathrm{~A}$ escolha da metáfora pelo professor não deixa de ser reveladora quanto ao sentido que o grupo dá à paternidade. Falando-se de uma situação em que duas pessoas têm um filho e uma delas é comparada à chocadeira, quem é a outra pessoa ausente de quem ninguém pensa ser necessária a presença para a sobrevivência desta criança? O galo? Isto seria uma interpretação ou uma dedução? Eis um ato psicanalítico.

A maneira como homens e mulheres estão colocados, dentro desta construção social das masculinidades e feminilidades, produzidas em diversos contextos histórico-socioculturais produzem formas diferenciadas da vivência do sofrimento psíquico. Os papéis desempenhados pelas mulheres na sociedade, como esposas, mães, educadoras, cuidadoras, além da participação cada vez mais essencial no mercado de trabalho, resulta em uma sobrecarga que pode levar a intenso sofrimento psíquico destas. Este sofrimento é intensificado por fatores decorrentes da discriminação sexual, como desfavorecimento econômico, trabalho em excesso, as violências doméstica e sexual. ${ }^{18}$

A professora encerra o assunto endossando a ideia predominante de que era da mãe, a responsabilidade por aquele menino. Mesmo quando ela revela que, em sua família, também houve um menino, filho de seu pai, ela parece remeter à mãe o não cuidado ao dizer que a criança ficou muito dividida, muito perdida porque sua mãe não sabia. Ninguém falou na responsabilidade do pai, por este ou por aquele outro menino.

Pode-se pensar que não há mãe desnaturada, vis to que o amor materno nada tem de natural. ${ }^{19} \mathrm{Em}$ vista das tantas neuroses de que sofrem os adultos, com raízes no passado familiar, de seus pais, de seus próprios conflitos e seus dramas pessoais, são por isto mesmo para seus filhos, muitas vezes, más companhias, mães más mesmo. E a isto, justifica-se evocando as tantas discriminações, frustrações, proibições, limitações de direitos a que as mulheres têm sido historicamente submetidas, quando lhe são recusadas carreiras tidas como masculinas, proclamadas incapacidades em determinados campos ao mesmo tempo em que lhe é confiado um empreendimento tão delicado, quanto a formação de um ser humano. ${ }^{19}$

$\mathrm{Na}$ sequência, a fala de outra professora refere a autoridade do pai em deixar a esposa colocar a roupa na cor que ele não julgue adequada para garantir a masculinidade de seu filho. Reparem que ela não fala em pai e mãe, o que igualaria o casal, em uma simetria. Mas, fala em pai, porque está falando na relação deste homem com o filho, protegendo-o. Mas, quando ela fala do pai da criança em relação à mulher, ela fala em esposa. Porque ela é esposa dele. Ou seja, é dele, propriedade dele. E isto fica implícito neste discurso, perpassado pelo sexismo. Ela duvida que qualquer pai deixe a esposa colocar no filho homem. Como se a mulher dependesse total e completamente desta permissão, da autorização e mais, que o filho precisasse desta proteção, da defesa do pai à sua macheza contra os erros que a mãe possa a vir cometer na criação.
M- Eu duvido que algum pai, qualquer pai, que deixe a esposa colocar no bebê, filho homem, um sapatinho que tenha um pouquinho de rosa ou amarelo...

Sexismo é uma postura de desprezo frente ao sexo oposto. ${ }^{20}$ Porém, esta expressão foi desconsiderada na edição de 1975, do Novo Dicionário Aurélio, assim como no Novo Michaelis dos anos oitenta, na sua edição inglesa, mas presente no Petit Robert, publicado em França nos anos noventa. Sexismo é atitude de discriminação em relação às mulheres. Mas, é importante lembrar que se trata de uma posição, que pode ser perpetrada, tanto por homens, quanto por mulheres; portanto, o sexismo está presente intragêneros, tanto quanto entre gêneros. Inscrita numa cultura falocrática, impregna o imaginário social e o prepara a um vasto conjunto de representações socialmente partilhadas, de opiniões e de tendência a práticas que desprezam, desqualificam, desautorizam e violentam as mulheres, tomadas como seres de menor prestígio social.

A próxima fala traz justamente um questionamento a respeito de uma criança trans menino, de onze anos de idade na época, que negava-se a vestir roupas convencionalmente femininas, mas vestia as bermudas do avô, as camisas deste e sentia-se bem a vontade assim. As professoras questionam a atitude da mãe em permitir esta opção ao filho e tratam de culpá-la, referindo o abandono suposto. Não se vê nestas falas, qualquer referência ao pai ou ao avô, de quem a criança veste as roupas, como se somente a mãe mesmo pudesse ser a responsável pela educação ou problemas que elas supõem ser a transexualidade já evidente.

M- Mas a mãe sempre vestiu ela desse jeito assim, guria? A mãe?

M- Ela é meio abandonada, né.

E os discursos vão validando os ditos machistas, como se fossem verdades imutáveis, e que vêm sobrevivendo, justamente por ser reeditadas e reproduzidas, atualizadas nas falas informais como nestas, entre jovens professores e professoras, que há pouco reclamavam das violências de alunas e alunos, apesar dos tantos cartazes espalhados pelas paredes, corredores da escola, falando de uma campanha contra o bullying.

\begin{abstract}
M- A família, sabe? E a gente, e eu vejo, como eu tenho só um filho, e que ele é preconceituoso também nessa parte, apesar de ele ser bem novo, porque eu acho assim também ele se criou muito sozinho com a gente, tendo esse parâmetro assim, que homem é homem, mulher é mulher.
\end{abstract}

Embora a escola deva ser o local de todos e todas, para além das condições sociais e etnias, preconceitos ali se fazem presente, reforçando as desigualdades. $\mathrm{Na}$ escola, enquanto espaço cultural por excelência, onde as crianças convivem grande parte de suas vidas, modelos de identidade de gênero, tanto nas interações cotidianas, quanto no material didático, são reforçados nos papéis estereotipados da identidade de meninos e meninas, quando mulheres são representadas comumente em situações de docilidade doméstica e inferioridade diante da capacidade dos homens na resolução de problemas $^{21}$. Valores relacionados a preconceitos, 
estigmatizadores de determinados grupos étnicos ou de gênero, circulam pela sociedade e são internalizados pelas alunas e alunos, influenciando na construção do autoconceito. A aceitação de papéis definidos para homens e mulheres, sem o questionamento dos discursos, naturaliza os comportamentos, tornando-os comuns e normais. ${ }^{21}$

\section{Jogo de saber}

Nas falas destas professoras e professores evidencia-se a angústia de quem se depara ainda com o desconhecido, expresso claramente em suas indagações. Pois, este é conteúdo não disponibilizado nas capacitações e formações destas e destes profissionais.

M- É uma moça... Não. É um rapaz... Um gay, né! Como é que a gente chama?

A professora não sabe como nomear aquela pessoa na sua frente. Ela enxerga uma moça. Ela enxerga uma pessoa do gênero feminino, mas não se autoriza a nominá-la como mulher. Então vacila, gagueja. Pergunta. Há estranheza na sua fala. Ninguém a socorre.

Se os movimentos das comunidades LGBT têm resultado em uma maior visibilidade, também têm trazido novos questionamentos às escolas, quando o tema provoca certa perturbação, já que exige a revisão de posicionamentos, dos paradigmas e a construção de novas referências a partir da consciência de que códigos culturais estão presentes em todas nossas manifestações sociais. ${ }^{22}$

$\mathrm{Na}$ fala seguinte, percebe-se a dificuldade de entendimento de possibilidades de quebra desta lógica dualista, em que tem que haver um pai e uma mãe na relação, e que duas mulheres só poderão viver um amor se ocuparem estes papéis estreitos de gêneros. A criança parece ter entendido muito bem.

- (...) Desde pequeno ele tava fazendo tratamento no psicólogo prá ir aceitar a amiga da mãe. A mãe se separou... Separou da amiga. Não dizia amiga pai... É amiga ou tia. Quando a mãe se separou, não quis mais a amiga dela, ele chegou um dia na escola muito triste, que a mãe tinha brigado com a amiga... Que ele queria ela de volta em casa, que já tava habituado os três dentro de casa. (...) Eu acho que foi a questão de trabalhar com o filho pra ele de alguma maneira, o manejo prá ele aceitar essa situação de uma família de estrutura diferenciada.

- Eu acho que não tem que chamar a outra de pai... Se ele tivesse um padrasto ele não ia chamar ele de pai...

- Eu achei interessante... Eu achei interessante que ele nunca disse prá mim: pai. É a amiga da mãe. Era amiga ou tia, sabe?

A homossexualidade cada vez mais pode ser entendida dentro das Ciências Humanas como uma configuração histórica específica em que tomam parte indivíduos com preferências homoeróticas, a partir de um referencial identitário, contrapondo a lógica essencialista biologicista, que buscava definições e componentes na essência biológica e psíquica de gays e lésbicas. ${ }^{23}$

Profissionais da educação precisam superar as concepções, historicamente construídas, a respeito das relações de gênero, assim como seus tabus e preconceitos relacionados à sexualidade. Isto implica em um movimento interno individual na busca por novas compreensões e mudanças de paradigmas já que é preciso refletir sobre sua própria história de vida, a fim de poder promover as transformações necessárias nas relações de gênero e uma educação sexual libertadora dos tabus e medos. ${ }^{24}$

M- Ela me disse assim: Sabe por que que eu bati nele? Porque ele me chamou de lésbica! (...) Ele me chamou de lésbica. $E$ eu fiquei pensando... $E$ agora? Agora eu digo: mas tu não é?

Neste discurso, a professora reproduz um diálogo com uma criança trans menino. A professora se atrapalha, pois a criança narra uma discussão que teve com um colega que a chamou de lésbica. Sua resposta foi um soco. Ela agrediu o menino que a chamou de lésbica. Fato comum, já que as crianças estão tendo dificuldades de entender o que está acontecendo com aquele colega, que tem nome de menina, que tem que usar o banheiro destinado às meninas, que se veste com roupas convencionalmente de meninos, com as amplas roupas do avô, e que não é lésbica. A professora também não o entende. A sensação desta professora, assim como de muitas outras e outros profissionais da educação, como se pode observar nesta discussão, é de que ela não sabe mais nada, enquanto que as crianças estejam aprendendo a lidar com estas mudanças mais rapidamente que elas e eles.

M- Uma vez uma pequeninha disse assim prá mim: Ô profe, tem um guri lá no nosso banheiro. Eu disse: Um guri? Quem é? Aquele lá, ó... Láaa. Ah, não. Ela é uma menina. E ela me olhou assim com uma cara que diz: Eu acho que tu olho errado. Ahahahahhaha. Essa professora não sabe nada...

M- Acho que ela é muito criança. Ela mora lá perto de casa... Ela mora lá perto de casa e meu filho um dia, ele entrou no pátio... Ela entrou no pátio, e ele disse: mãe, aquele gurizinho tá batendo lá! Daí eu tive que explicar: L, não é, não é... Ele é uma menina... Daí eu tive que explicar todo o processo e ele ficou me olhando... ãaa... Ah, mas parece um menino, né mãe? Daí, sabe... Daí tu tem que explicar por causa da criança é difícil de... Imagina um adulto... Uma criança assim, né...

A heterossexualidade aparece como o padrão, a referência que balizará todas as outras sexualidades, de forma que esta forma normativa, ao encarnar um ideal, passa a ser constitutiva de uma forma específica de dominação: o heterossexismo. Este é a crença em uma hierarquia das sexualidades, outorgando superioridade à heterossexualidade. Sendo assim, todas as demais formas de sexualidade são consideradas incompletas, acidentais, perversas, ou ainda, patológicas, criminosas, imorais e destruidoras da civilização. ${ }^{25}$

A percepção de que haja uma grande confusão, já que elas e eles próprios, profissionais da educação, estão muito atrapalhados com estas questões de gênero e sexualidades, pode estar fazendo com que se 
sintam na necessidade de ajudar as crianças, meninos e meninas, tentando explicar-lhes o que nem eles e elas estão conseguindo entender. Como no discurso acima, da professora, em que ela fala da conversa dela com seu filho pequeno. Esta atitude, em relação às crianças e adolescentes transexuais, além de desnecessária, pois a criança não havia perguntado se o visitante era um menino ou uma menina, ainda gera um mal estar, um desconforto que vulnerabiliza a criança que é denunciada. Assim como acontece quando o nome de registro é usado na chamada, o uso do banheiro, a fila separando por sexos, Educação Física e outras tantas situações em que o sexo da pessoa é posto em evidência, a antecede, como se nada mais importasse naquele momento.

\section{E se fosse comigo?}

Mas, este discurso vai mais além. Ele fala desta dificuldade em explicar ao filho algo difícil para ela mesma. Algo que, para o filho pareceu tão fácil entender. Ele viu um menino e para ele era um menino. Para aquela professora aquele não podia ser um menino e ela precisava desfazer o engano. Ela precisa corrigir aquilo. Porque ela é uma educadora e uma mãe. Como ouvimos nos discursos desde o início deste estudo. Em tantas falas e em tantas outras que não couberam aqui. $E$ as mulheres, segundo o que elas e eles disseram naquele grupo de discussões, são responsáveis pelos filhos e culpadas também. Não podem pensar em seus amores, não podem pensar em seus desejos, enquanto seus filhos não estiverem criados. Porque, se a menina veste roupas de menino e pensa que é um menino, a culpa é da mãe. Foi o que elas e eles disseram. Por isto, Ihes escapa nas palavras o medo da culpa, cuja pena já está sentenciada em toda esta rejeição machista lesbo-trans-homofóbica que se voltaria contra ela e sua criança. E ela “choca"...

- A situação. A gente vendo de longe é... A gente tem um olhar diferente... Agora, se acontece na família da gente... Eu acho que... Aí a gente... Sofre muito. Não sabe?

- E se fosse na minha família?

- Prá mim assim foi, assim a gente... Mas a maioria fala que é normal. Mas no momento que te depara com uma situação e uma cena dessas não é tão normal. Eu já me choco. Eu fico imaginando o dia em que pode acontecer na família, sabe? Como tu vai conduzir. Porque enquanto tu vê no outro, é fácil, mas quando tiver próximo de ti, da tua família, ou assim, perto...

A condição feminina na contemporaneidade, decorrente do modelo patriarcal, confere às mulheres uma posição de desvalorização, em relação aos homens, em relações hierarquizadas que devem ser problematizadas pela psicologia. ${ }^{26}$

Muitas vezes a mulher tem dificuldades em conciliar o trabalho fora de casa e os interesses e cuidados de seus filhos. Isto porque o trabalho feminino ainda ocorre, frequentemente, em regime de escravidão, já que os cuidados, a guarda e educação das crianças ainda são de responsabilidade da mulher. Trata-se de uma carência social, justificada em uma lei inscrita no céu ou nas entranhas da terra que determina que a mãe e o filho se pertençam exclusivamente, em mútua pertinência, que na verdade constitui uma dupla e nefasta opressão. $^{19}$

Seria melhor para o bem da criança que a mãe fosse uma pessoa completa e não mutilada. Uma mulher que encontrasse em seu trabalho, em sua relação social, a realização pessoal e que não a buscasse, através desta criança, tiranicamente..$^{19}$

\section{CONSIDERAÇÕES FINAIS}

Esta análise parcial dos discursos de profissionais da educação resultou em uma percepção da homossexualidade e transexualidade como anormais, em flagrante rejeição a estas, embora o esforço de algumas profissionais em tentar compreender estes processos.

Neste discurso marcado pela reprodução de expressões de discriminação de gênero, representativas de definições estáticas de papéis de mulher e de homem, soavam como ameaças a quem ousasse escapar ao determinismo social machista. Percebe-se também, na angústia dos questionamentos, o intenso sofrimento daquelas profissionais, acreditando que fosse preciso e possível evitar a homossexualidade e a transexualidade, na medida em que, embora não soubessem o que fazer, percebiam-se ainda como responsáveis por manter a ordem ditada pelas rígidas regras sexistas e heterossexistas.

Pode-se pensar que o desconhecimento a respeito das questões de gênero e sexualidade, assim como orientação sexual e identidade de gênero, estejam dificultando a aceitação da liberdade de expressão da sexualidade, a que todos e todas têm direito, na sociedade. Pois, a ausência de acesso ao amplo debate e estudos dos campos das ciências sociais e humanas a respeito deste tão importante aspecto da constituição da/os sujeita/os, ocasiona que profissionais deparem-se com a realidade provida/os apenas de conceitos morais e religiosos cristalizados, o que impossibilita reflexões aprofundadas sobre a complexidade da condição humana.

Além disto, o fato de profissionais da educação encontrarem-se aprisionados neste estreito espaço de masculinidades e feminilidades estereotipados, dentro desta lógica binária e excludente de uma sociedade hierarquizadora, seus pressupostos culturais, podem estar fazendo com que se sintam também responsáveis pela direção que os desejos e afetos de alunos e alunas estejam tomando.

Procede a conclusão de que este fenômeno aponta para a necessidade de criação de políticas públicas voltadas não somente para facilitar a capacitação destes e destas profissionais nos campos de estudos da sexualidade humana mas, sobretudo para viabilizar uma interdisciplinaridade dentro das escolas, tornando possível a discussão de questões que até bem pouco tempo eram tratadas somente no âmbito pessoal e individual.

\section{REFERÊNCIAS}

1. Foucault Michel. História da sexualidade I: A vontade de saber. Rio de Janeiro: Graal, 1985.

2. Prado Marco Aurélio M, Machado FV. Preconceitos contra 
homossexualidades: a hierarquia da invisibilidade. São Paulo: Cortez, 2008.

3. Louro Guacira Lopes. O corpo educado: pedagogias da sexualidade. Tradução dos artigos: Tomaz Tadeu da Silva. Belo Horizonte: Autêntica, 2007.

4. Butler Judith. Cuerpos que importan: sobre los limites materiales y discursivos Del "sexo". Buenos Aires: Paidós, 2002.

5. Butler, Judith. Problemas de Gênero - Feminismo e Subversão da Identidade, Ed: Civilização brasileira, Rio de Janeiro, 2003.

6. Louro Guacira Lopes. Heterornormatividade e homofobia. In Brasil: Diversidade Sexual na Educação: problematizações sobre a homofobia nas escolas. Brasília: Ministério da Educação, Secretaria de Educação Continuada, Alfabetização e Diversidade, UNESCO, 2009.

7. Bento Berenice AM. O que é transexualidade. São Paulo. Ed. Brasiliense. 2008.

8. Rios Roger Raupp. Homofobia na Perspectiva dos Direitos Humanos e no Contexto dos Estudos sobre Preconceito e Discriminação. In Brasil. Diversidade Sexual na Educação: problematizações sobre a homofobia nas escolas- Brasília : Ministério da Educação, Secretaria de Educação Continuada, Alfabetização e Diversidade, UNESCO, 2009.

9. Weller Wivian. Grupos de discussão na pesquisa com adolescentes e jovens: aportes teórico-metodológicos e análise de uma experiência com o método. Educ Pesqui 2006;32(2):241-60.

10. Ribeiro Daniel. Eu não quero voltar sozinho. Produzido por Diana Almeida (curta metragem, ficção, 15', cor, 35mm. dolby SR ) 2012. DVD.

11. Spink Mary Jane P, Gimenes Maria G. Práticas discursivas e produção de sentido: Apontamentos metodológicos para a análise de discursos sobre a saúde e a doença. Saude Soc 2014;3(2):149-71. doi: 10.1590/S0104 12901994000200008.

12. Spink Mary Jane $P$, Medrado Benedito. Produção de sentido no cotidiano: uma abordagem teórico-metodológica para análise das práticas discursivas in Práticas discursivas e produção de sentido no cotidiano: Aproximações teóricas e metodológicas. Org.: Mary Jane Spink. Rio de Janeiro. Ed. Centro Edelstein de Pesquisas Sociais. 2013.

13. Ferreira Aurélio $\mathrm{BH}$. Mini dicionário da língua portuguesa- $2^{\mathrm{a}}$ ed. RJ. Ed. Nova Fronteira. 1989.
14. Salih Sara. Judith Butler e a Teoria Queer. Trad. e Nota Guacira Louro Lopes. Belo Horizonte. Ed.: Autêntica. 2012.

15. Lips Hilary. Sex and gender. Mountain View, CA: Mayfield Publishing. 1993.

16. Lott Berenice, Maluso Diane. (1995). Introduction: Framing the questions. Em B. Lott e D. Maluso (Orgs.). The social psychology of interpersonal discrimination (pp. 1-11). New York: The Guilford Press.

17. Orlandi Eni P. Análise do discurso: princípios e procedimentos. Campinas, SP: Pontes, 1999.

18. Santos Anna Maria CC. Articular saúde mental e relações de gênero: dar voz aos sujeitos silenciados. Ciênc Saúde Colet 2009;14(4):1177-82. doi: 10.1590/S141381232009000400023

19. Beauvoir Simone de. O segundo sexo. Tradução Sérgio Milliet- $2^{a}$ ed. RJ. Nova Fronteira. 2v. 2009

20. Smigay Karin EV. Sexismo, homofobia e outras expressões correlatas de violência: desafios para a psicologia política. Disponívelemhttp://www.pucminas.br/imagedb/documento/ DOC DSC NOME ARQUI20041214154032.pdf Acesso em dez. $201 \overline{4}$

21. Pereira Sissi AM. O respeito às diferenças, educação e relações de gênero in Diversidade e transversalidade nas práticas educativas/Organizadoras Marília Lopes de Campos, Ana Cristina Souza dos Santos- Rio de Janeiro: Nau: EDUR, 2010.

22. Louro Guacira Lopes. Gênero, sexualidade e educação: Uma perspectiva pós-estruturalista - Petrópolis, RJ: Vozes, 2003.

23. Garcia Marcos RV, Wolf AG, Oliveira EV, Souza JTF, Gonçalves LO, Oliveira M. Não podemos falhar: A busca pela normalidade em famílias homoparentais. in Conjugalidades, parentalidades e identidades lésbicas, gays e travestis/ Organizadores Miriam Pillar Grossi, Anna Paula Uziel e Luiz Mello- Rio de Janeiro: Garamond, 2007.

24. Figueiró Mary Neide Damico. Formação de Educadores Sexuais: adiar não é mais possível. São Paulo: Mercado das Letras, 2006.

25. Borrillo Daniel. Homofobia: história e crítica de um pensamento. Belo Horizonte: Autêntica Editora, 2010.

26. Narvaz Martha. Submissão e resistência: explodindo o discurso patriarcal da dominação feminina [dissertação]. Porto Alegre (RS): Universidade Federal do Rio Grande do Sul; 2005.

Como citar: PUGLIA, Joana do Prado. Sexismo na escola: Presente!. Cinergis, Santa Cruz do Sul, v. 17, n. 3, set. 2016. ISSN 2177-4005. Disponível em: <https://online.unisc.br/seer/index.php/cinergis/article/view/7845>. Acesso em: 11 out. 2016. doi:http://dx.doi.org/10.17058/cinergis.v17i3. 7845. 